\title{
The Decision to Buy or Sell Insurance under Constant Relative Risk Aversion
}

\author{
by George G. Szpiro*
}

1. In a recent paper (Szpiro, [1985]) three statements were derived which are useful in describing an individual's insurance behavior. Using the methodology described there, it was then shown empirically (Szpiro, [1986]) that the hypothesis of constant relative risk aversion (CRRA) cannot be rejected; similar results had been found earlier, for instance, by Friend and Blume [1975].

The main result of the above paper is an approximation for the optimal insurance coverage, $I$, when the probability of loss is small:

$$
I=L-\lambda / r(W) .
$$

( $L$ is the amount at risk, $W$ stands for wealth, $r(W)$ is the Pratt-Arrow function of risk aversion, and $\lambda$ is the insurance loading factor.) This equation was derived using a two-term Taylor approximation, under the assumption of either total loss or no loss. ${ }^{1}$

2. Given the evidence supporting CRRA, it is useful to develop the methodology further, thereby deriving a necessary and sufficient condition to determine whether an individual (or a corporate entity) will buy or sell insurance.

\section{Statement:}

If an individual conforms to the hypothesis of CRRA, and under conditions of limited liability, he/she will buy or sell insurance, depending on whether the loading factor is less than or greater than the degree of partial relative risk aversion. Under conditions of

* School of Business Administration, Hebrew University of Jerusalem, Israel. This article was written while I was at the Wharton School, University of Pennsylvania.

I would like to thank Eric Briys for a suggestion which greatly expanded the applicability of this paper.

${ }^{1}$ Such a Taylor expansion is actually better than is generally believed. See, for example, Samuelson [1970] and Tsiang [1972]. 
full liability, he/she will buy or sell insurance, depending on whether the loading factor is less than or greater than the degree of relative risk aversion. ${ }^{2}$

The proof of the statement goes as follows: since CRRA implies that $r(W)$ is of the form $c / W$, where $c$ is the degree of relative risk aversion (RRA), we get, from equation (1),

$$
I=L-\lambda W / c
$$

Let us first investigate the case where liability is limited (e.g., property insurance). Dividing both sides of equation (2) by $L$, the amount at risk, we obtain

$$
I / L=1-\frac{\lambda}{c L / W}
$$

For CRRA, the term $c L / W$, that is, the degree of RRA, multiplied by the fraction of wealth at risk, was defined by Zeckhauser and Keeler [1970], and by Menezes and Hanson [1970] as partial relative risk aversion (PRRA). ${ }^{3}$ Writing $V / L$ for the fraction of the total amount at risk left uninsured, we have,

$$
V / L=\frac{\lambda}{c L / W}
$$

Thus, whenever the loading factor is less than the degree of PRRA, $V / L$ takes on a value smaller than one, which indicates the purchase of at least partial insurance. On the other hand, whenever the loading factor exceeds the degree of PRRA, $V / L$ is greater than unity; in this case the individual is willing to leave a multiple of the amount at risk uninsured, that is, he would want to sell insurance. ${ }^{4}$

It can easily be seen that the corner solutions $\lambda=0$ and $\lambda=$ PRRA lead to full insurance and to no insurance, respectively. For negative values of $c, V / L$ becomes negative, which implies that the fraction insured is greater than the amount at risk (i.e., overinsurance or, in other words, gambling) as it must be for risk takers.

In the case of full liability (e.g., property/liability insurance) the amount at risk, $L$, is equal to total wealth (a person can be sued "for all he's worth") and we obtain, after dividing both sides of equation (2) by $W$,

$$
I / W=1-\lambda / c
$$

\footnotetext{
${ }^{2}$ Since the quality of the approximation which was used to derive equation (1) diminishes with increasing $\lambda$, the results for the full liability case should be taken as indicative only.

${ }^{3} \mathrm{~A}$ recent paper describing the relationship between absolute, relative, and partial relative risk aversion is by Briys and Eeckhoudt [1985].

${ }^{4}$ Of course, with different loading factors prevailing in, say, different lines, an individual may both buy and sell insurance simultaneously.
} 
and

$$
V / W=\lambda / c .5
$$

Again, we see that if $\lambda$ is greater than the degree of RRA, the proportion of wealth which is uninsured is greater than one, which means that the individual is willing to sell insurance. (As above, the corner solutions $\lambda=0$, and $\lambda=c$ lead to full insurance and to no insurance, respectively.)

Les us end with a numerical example. In Szpiro [1986] it is shown that the degree of relative risk aversion is about 1.4. Thus, in the case of limited liability, where $L$ is limited to, say, one quarter of total wealth, the individual would want to sell insurance whenever the loading factor is greater than $35 \%$. For the case of full liability, the individual will buy partial insurance whenever the loading factor is less than $140 \%$; with a loading factor equal to $140 \%$, he will buy no insurance, and with a loading factor greater than $140 \%$, the individual will want to sell insurance.

\section{REFERENCES}

BRIYS, E., and EECKHOUDT, L. [1985]: "Relative risk aversion in comparative statics: a comment", American Economic Review, 75 (March 1985), 281-283.

FRIEND, I., and BLUME, M.E. [1975]: "The demand for risky assets", American Economic Review, 56(December 1975), 327-351.

MENEZES, C.F., and HANSON, D.L. [1970]: "On the theory of risk aversion", International Economic Review, 11 (October 1970), 481-487.

SAMUELSON, P. [1970]: "The fundamental approximation theorem of portfolio analysis in terms of means, variances and higher moments", Review of Economic Studies, 37 (October 1970), 537-542.

SZPIRO, G.G. [1985]: "Optimal insurance coverage”, Journal of Risk and Insurance, 52 (December 1985), 704-710.

SZPIRO, G.G. [1986]: "Measuring risk aversion: An alternative approach", Review of Economic and Statistics, 68 (February 1986), 156-159.

TSIANG, S.C. [1972]: "The rationale of the mean-standard deviation analysis, skewness preference, and the demand for money", American Economic Review, 62 (June 1972), 354-371.

ZECKHAUSER, R., and KEELER, E. [1970]: “Another type of risk aversion”, Econometrica, 38 (September 1970), 661-665.

\footnotetext{
${ }^{5}$ Compare this formula with Friend and Blume's equation (5), which states that the proportion of net worth placed in the portfolio of risky assets is equal to the market price of risk, divided by the degree of relative risk aversion.
} 